\title{
ANALISIS KEBUTUHAN DAN PENGETAHUAN MASYARAKAT TERHADAP PELAYANAN KESEHATAN DI PUSKESMAS SEMEMI KOTA SURABAYA
}

\author{
Dewi Mardahlia', Zulkifli Umar², Zuhrotusy-Syarifah Qurrotu'aini ${ }^{3}$, Indah Triesna Uyang ${ }^{4}$ \\ ${ }^{1}$ STIKES Mutiara Mahakam Samarinda \\ ${ }^{2}$ STIKES Mutiara Mahakam Samarinda \\ ${ }^{3}$ STIKES Mutiara Mahakam Samarinda \\ ${ }^{4}$ STIKES Mutiara Mahakam Samarinda
}

Alamat korespondensi: (dewimardahlia@gmail.com/085246787518)

\begin{abstract}
ABSTRAK
Pelayanan kesehatan merupakan suatu upaya yang diselenggarakan sendiri atau organisasi untuk memelihara dan meningkatkan kesehatan, mencegah dan menyembuhkan penyakit serta memulihkan kesehatan perorangan, keluarga, keluarga dan ataupun masyarakat. Tujuan penelitian ini adalah untuk menganalisis kebutuhan dan pengetahuan masyarakat terhadap pelayanan kesehatan di Puskesmas Sememi Kota Surabaya. Penelitian ini merupakan jenis penelitian Analisis deskriptif. Sampel diambil secara purposif sampling, dengan mengambil responden di masing-masing kelurahan yang termasuk wilayah kerja Puskesmas Sememi yaitu Sememi, Kandangan, Tambakosowilangun dan Romo kalisari. Masing-masing kelurahan diambil 25 orang responden, sehingga total responden dalam penelitian ini adalah 100 orang responden. Hasil penelitian ini menunjukan bahwa proritas masalah yang perlu diselesaikan adalah program Kampung ASI dan Pelayanan Pijat Bayi. Kebutuhan masyarakat terhadap program ASI Eksklusif sudah sangat besar $(100 \%)$, namun masyarakat masih banyak yang belum mengetahui (65\%). Kampung ASI juga merupakan salah satu program unggulan di Puskesmas Sememi. Sedangkan pelayanan pijat bayi merupakan program pendukung yang juga sangat dibutuhkan masyarakat, dan sudah disediakan oleh Puskesmas. Akan tetapi masih banyak masyarakat yang belum mengetahuinya sehingga masih sedikit masyarakat yang memanfaatkan pelayanan tersebut. Kesimpulan dalam penelitian ini adalah masyarakat menyatakan membutuhkan program/pelayanan Kampung ASI dan Pelayanan Pijat Bayi namun lebih dari $50 \%$ masyarakat tidak tahu sehingga tingkat partisipasi masyarakatnya menjadi kurang optimal.
\end{abstract}

Kata Kunci: Kebutuhan, Pengetahuan, Pelayanan Kesehatan

\section{PENDAHULUAN}

Pelayanan kesehatan menurut Depkes RI (2009) adalah setiap upaya yang diselenggarakan sendiri atau secara bersamasama dalam suatu organisasi untuk memelihara dan meningkatkan kesehatan, mencegah dan menyembuhkan penyakit serta memulihkan kesehatan perorangan, keluarga, kelompok dan ataupun masyarakat.Salah satu perubahan besar yang masih berlangsung di dalam sistem kesehatan di Indonesia adalah perubahan dalam Sistem Jaminan Kesehatan Nasional (JKN). Di era Jaminan Kesehatan Nasional (JKN) ini, pelayanan kesehatan tidak lagi terpusat di rumah sakit atau fasilitas kesehatan (faskes) tingkat lanjutan.Pelayanan kesehatan harus dilakukan secara berjenjang sesuai dengan kebutuhan medisnya, dimulai dari faskes primer seperti puskesmas atau klinik.

Pemberian pelayanan publik yang berkualitas dan mampu memberikan kepuasan bagi masyarakat merupakan kewajiban yang harus dilakukan oleh pemerintah. Puskesmas sebagai ujung tombak dan sekaligus sebagai tolok ukur pelayanan publik dibidang kesehatan, merupakan salah satu pilar dalam memenuhi tuntutan reformasi birokrasi. Faktanya, penilaian kualitas pelayanan kesehatan di Puskesmas menunjukan hasil yang belum memenuhi standar kualitas sehingga target penurunan Angka Kematian Ibu (AKI) dan Angka Kematian Bayi (AKB) sulit dicapai.

Menghadapi persoalan yang demikian, maka standarisasi Puskesmas melalui sistem akreditasi merupakan suatu keniscayaan yang mesti dilakukan untuk mampu bertindak secara professional, dengan senantiasa mengembangkan sistem manajemen yang baik serta mengembangkan program inovasi sehingga fungsi sebagai pemberi pelayanan kesehatan individu maupun kelompok atau masyarakat dapat berjalan dengan baik dan bermutu.

Saat ini, di lingkup Dinas Kesehatan Kota Surabaya telah ada Puskesmas yang sudah memperoleh status akreditasi. Salah 
satunya adalah Puskesmas Sememi yang memperolehnya pada tahun 2016. Menjadi sesuatu yang menarik untuk dipelajari lebih lanjut bagaimana Puskesmas Sememi berproses hingga menuai hasil terakreditasi dari Kementerian Kesehatan Republik Indonesia.

\section{BAHAN DAN METODE}

Lokasi, Populasi, Sampel

Penelitian ini dilaksanakan saat Residensi di Puskesmas Sememi Kota Surabaya pada tanggal 24 Agustus s/d 3 September 2016.

Sampel diambil secara purposif sampling, dengan mengambil responden di masing-masing kelurahan yang termasuk wilayah kerja Puskesmas Sememi yaitu Sememi, Kandangan, Tambakosowilangun dan Romo kalisari. Masing-masing kelurahan diambil 25 orang responden, sehingga total responden dalam penelitian ini adalah 100 orang responden

Pengambilan data dilakukan dengan cara membagikan kuesioner kepada bidan di 4 (empat) kelurahan, kemudian bidan membagikan ke masyarakat secara merata. Jangka waktu pengambilan data tersebut adalah 4 (empat) hari.

Kuesioner yang sudah terisi kemudian dientri ke dalam SPSS. Data diolah dengan analysis deskriptif.

\section{HASIL PENELITIAN}

Menurut hasil dan analisis data survei tentang kebutuhan dan pengetahuan masyarakat terhadap pelayanan kesehatan di Puskesmas Sememi Tahun 2016 dapat dilihat pada tabel 1 dan 2 .

Tabel 1 Kebutuhan Masyarakat Terhadap pelayanan kesehatan di Puskesmas Sememi Tahun 2016

\begin{tabular}{|c|c|c|c|c|c|c|c|}
\hline \multirow{3}{*}{ No } & \multirow{3}{*}{ URAIAN } & \multicolumn{6}{|c|}{ KEBUTUHAN } \\
\hline & & \multicolumn{2}{|c|}{ BUTUH } & \multicolumn{2}{|c|}{$\begin{array}{c}\text { TIDAK } \\
\text { BUTU } \\
\text { H }\end{array}$} & \multicolumn{2}{|c|}{ TOTAL } \\
\hline & & $\mathrm{n}$ & $\%$ & $\mathrm{n}$ & $\%$ & $\mathrm{n}$ & $\%$ \\
\hline 1 & $\begin{array}{l}\text { Mobile } \\
\text { kinik }\end{array}$ & 95 & 95 & 5 & 5 & $\begin{array}{r}10 \\
0\end{array}$ & 100 \\
\hline 2 & $\begin{array}{l}\text { Kunjungan } \\
\text { neonatal } \\
\text { komplikasi }\end{array}$ & 100 & 100 & 0 & 0 & $\begin{array}{r}10 \\
0\end{array}$ & 100 \\
\hline 3 & $\begin{array}{l}\text { Kampung } \\
\text { Asi }\end{array}$ & 100 & 100 & 0 & 0 & $\begin{array}{r}10 \\
0 \\
\end{array}$ & 100 \\
\hline 4 & $\begin{array}{l}\text { Pengambil } \\
\text { an sampel } \\
\text { depo air } \\
\text { minum }\end{array}$ & 97 & 97 & 3 & 3 & $\begin{array}{r}10 \\
0\end{array}$ & 100 \\
\hline 5 & $\begin{array}{l}\text { Penyuluha } \\
\text { n NAPZA }\end{array}$ & 96 & 96 & 4 & 4 & $\begin{array}{r}10 \\
0\end{array}$ & 100 \\
\hline 6 & Kunjungan & 96 & 96 & 4 & 4 & 10 & 100 \\
\hline
\end{tabular}

\begin{tabular}{|c|l|c|c|c|c|c|c|}
\hline & $\begin{array}{l}\text { lumah } \\
\text { penderita } \\
\text { gangguan } \\
\text { jiwa }\end{array}$ & & & & & & \\
\hline 7 & $\begin{array}{l}\text { Demo } \\
\text { TOGA }\end{array}$ & 100 & 100 & 0 & 0 & $\begin{array}{r}10 \\
0\end{array}$ & 100 \\
\hline 8 & Pijat Bayi & 100 & 100 & 0 & 0 & $\begin{array}{r}10 \\
0\end{array}$ & 100 \\
\hline 9 & $\begin{array}{l}\text { Pelayanan } \\
\text { Paliatif }\end{array}$ & 85 & 85 & $\begin{array}{r}1 \\
5\end{array}$ & 15 & $\begin{array}{r}10 \\
0\end{array}$ & 100 \\
\hline
\end{tabular}

Dari tabel 1 menunjukkan bahwa ratarata masyarakat membutuhkan program pelayanan Kesehatan. Jenis layanan kesehatan yang sangat dibutuhkan masyarakat (100\%) adalah kunjungan neonatal komplikasi, kampung $\mathrm{ASI}$, demo TOGA dan pijat Bayi.

Tabel 2 Pengetahuan Masyarakat Terhadap pelayanan kesehatan di Puskesmas Sememi Tahun 2016

\begin{tabular}{|c|c|c|c|c|c|c|c|}
\hline \multirow{3}{*}{ No } & \multirow{3}{*}{ URAIAN } & \multicolumn{6}{|c|}{ PENGETAHUAN } \\
\hline & & \multicolumn{2}{|c|}{ TAHU } & \multicolumn{2}{|c|}{$\begin{array}{l}\text { TIDAK } \\
\text { TAHU }\end{array}$} & \multicolumn{2}{|c|}{ TOTAL } \\
\hline & & $\mathrm{n}$ & $\%$ & $n$ & $\%$ & $\mathrm{n}$ & $\%$ \\
\hline 1 & $\begin{array}{l}\text { Mobile } \\
\text { kinik }\end{array}$ & 55 & 55 & 45 & 45 & 100 & 100 \\
\hline 2 & $\begin{array}{l}\text { Kunjungan } \\
\text { neonatal } \\
\text { komplikasi }\end{array}$ & 57 & 57 & 43 & 43 & 100 & 100 \\
\hline 3 & $\begin{array}{l}\text { Kampung } \\
\text { Asi }\end{array}$ & 35 & 35 & 65 & 65 & 100 & 100 \\
\hline 4 & $\begin{array}{l}\text { Pengambil } \\
\text { an sampel } \\
\text { depo air } \\
\text { minum }\end{array}$ & 58 & 58 & 42 & 42 & 100 & 100 \\
\hline 5 & $\begin{array}{l}\text { Penyuluha } \\
\text { n NAPZA }\end{array}$ & 62 & 62 & 38 & 38 & 100 & 100 \\
\hline 6 & $\begin{array}{l}\text { Kunjungan } \\
\text { rumah } \\
\text { penderita } \\
\text { gangguan } \\
\text { jiwa }\end{array}$ & 55 & 55 & 45 & 45 & 100 & 100 \\
\hline 7 & $\begin{array}{l}\text { Demo } \\
\text { TOGA }\end{array}$ & 36 & 36 & 54 & 54 & 100 & 100 \\
\hline 8 & Pijat Bayi & 40 & 40 & 60 & 60 & 100 & 100 \\
\hline 9 & $\begin{array}{l}\text { Pelayanan } \\
\text { Paliatif }\end{array}$ & 37 & 37 & 63 & 63 & 100 & 100 \\
\hline
\end{tabular}

Dari tabel 2 menunjukkan bahwa Program yang paling tidak dikenal oleh masyarakat adalah kampung ASI sebesar $65 \%$ dan pijat bayi sebesar $60 \%$.

Berdasarkan Tabel 1 dan tabel 2, dapat diketahui bahwa proritas masalah yang perlu diselesaikan adalah program Kampung ASI dan Pelayanan Pijat Bayi. Kebutuhan masyarakat terhadap program ASI Eksklusif sudah sangat besar (100\%), namun masyarakat masih banyak yang belum mengetahui (65\%). Kampung ASI juga merupakan salah satu program unggulan di 
Puskesmas Sememi. Sedangkan pelayanan pijat bayi merupakan program pendukung yang juga sangat dibutuhkan masyarakat, dan sudah disediakan oleh Puskesmas. Akan tetapi masih banyak masyarakat yang belum mengetahuinya sehingga masih sedikit masyarakat yang memanfaatkan pelayanan tersebut.

\section{PEMBAHASAN}

Berdasarkan hasil survei, analisis dan identifikasi masalah, terdapat 2 (dua) masalah yang perlu dicarikan solusi, sehingga bisa meningkatkan capaian program di Puskesmas Sememi. Di Puskesmas Sememi terdapat 2 (dua) program yaitu kunjungan neonatal komplikasi dan supervisi fasilitatif yang kebutuhan masyarakatnya tinggi namun program/pelayanan tersebut kurang popular di masyarakat sehingga masih banyak masyarakat yang belum tahu dan tingkat partisipasi masyarakatnya masih belum optimal.

Untuk mewujudkan perilaku masyarakat agar berperan aktif dalam program kesehatan terutama program kunjungan neonatal komplikasi dan supervisi fasilitatif maka diperlukan pendidikan serta penyebarluasan informasi program yang efektif, sehingga masyarakat menjadi banyak yang tahu, mengerti, niat dan diwujudkan dalam bentuk perbuatan ikut berpartisipasi aktif sesuai perannya masing-masing.

Pendekatan pemasaran sosial bisa dilakukan untuk mencapai tujuan tersebut. Tujuan utama pemasaran sosial adalah social good atau bisa bertujuan untuk menghasilkan perencanaan yang optimum atas social change. Pemasaran sosial yang efektif dapat meningkatkan kesadaran, pengetahuan, mempengaruhi sikap, menunjukkan manfaat perubahan dan memperkuat pengetahuan. Pemasaran sosial juga berusaha menunjukkan ketrampilan, mendorong melakukan tindakan dengan segera, meningkatkan permintaan akan jasa, membuktikan bahwa mitos salah, mempengaruhi norma, meningkatkan jumlah partisipan pelayanan kesehatan masyarakat (Frederiksen, 1984).

Tahapan pemasaran sosial merupakan suatu siklus yang saling berkesinambungan. Menurut (Kotler, 2002), terdapat 10 langkah dalam pengembangan kampanye pemasaran sosial adalah sebagai berikut :

1. Menentuka latar belakang, tujuan dan fokus

2. Melakukan analisa situasi

3. Memilih target sasaran
4. Menetapkan Sasaran dan Tujuan Pemasaran

5. Mengidentifikasi faktor yang mempengaruhi adopsi perilaku

6. Merancang pernyataan posisioning

7. Mengembangkan strategi bauran pemasaran $4 \mathrm{P}$

8. Menyusun rencana monitoring dan evaluasi

9. Menetapkan anggaran dan mencari sumber pendanaan

10.Melengkapi rencana pelaksanaan kampanye dan manajemen

Sebagai puskesmas Paripurna semua program dan kegiatan yang ada di Puskesmas Sememi telah dilengkapi dengan KAK (Kerangka Acuan Kegiatan) yang didalamnya memuat latar belakang, tujuan, sasaran, fokus program, sumber pembiayaan dan monitoring evaluasi. Sehingga bisa disimpulkan bahwa sebagian besar tahapan dari perencanaan pemasaran sosial sebagaimana tersebut diatas telah dilakukan, namun mungkin tahapan yang perlu diakukan adalah mengidentifikasi faktor yang mempengaruhi adopsi perilaku dan mengembangkan strategi bauran pemasaran $4 \mathrm{P}$.

Salah satu cara yang bisa digunakan untuk mengidentifikasi faktor yang mempengaruhi adopsi perilaku adalah dengan melakukan survei terhadap masyarakat yang menjadi target sasaran. Dari hasil survei tersebut bisa diketahui alasan masyarakat untuk mau ikut berpartisipasi dan apa yang menjadi hambatan mereka untuk berpartisipasi dalam program/kegiatan.

Toolbox pemasaran biasa terdiri dari empat komponen utama 4P : Produk, Price (harga), Place (tempat) dan Promotion (promosi). 4P ini harus dikembangkan dan disajikan dalam urutan sebagai berikut, dengan strategi produk pada awal urutan dan strategi promosi diakhir. Meskipun strategi tersebut dilakukan secara berurutan namun tidak dikembangkan secara terpisah atau sering disebut "bauran" 4P. Sinergi dari 4P yang memungkinkan kampanye pemasaran sosial yang sukses (Supriyanto, S. \& Wulandari, R.D, 2011).

Di Puskesmas Sememi untuk 2 (dua) program tersebut bisa dilakukan bauran $4 \mathrm{P}$ dengan cara sebagai berikut :

1. Strategi Produk

Produk dari pelayanan pijat bayi adalah manfaat yang dirasakan oleh masyarakat ketika bayinya dipijat secara rutin yaitu bayi menjadi jarang rewel, tidurnya nyenyak, nafsu makannya meningkat, tidak gampang sakit dan tumbuh kembangnya menjadi optimal. Produk tersebut bisa diwujudkan 
dalam bentuk fitur utama dalam kampanye tentang pijat bayi.

Produk utama dari Kampung ASI adalah manfaat yang dirasakan ketika semua bayi di satu wilayah mendapatkan ASI Ekslusif yaitu bayi menjadi tidak mudah terkena penyakit, dukungan keluarga dan masyarakat di lingkungan sekitar agar ibu memberikan ASI Ekslusif menjadi besar.

2. Strategi Harga

Strategi harga sangat tepat untuk menggambarkan biaya yang akan "dibayar" saat mengadopsi perilaku atau biaya yang bisa dihemat ketika masyarakat sudah berperilaku sesuai dengan tujuan program. Strategi harga yang paling tepat untuk program kampung ASI dan pijat tradisional adalah dengan menekankan biaya apa saja yang bisa dihemat ketika bayi di beri ASI eksklusif antara lain besarnya susu formula yang harus dibeli ketika bayi tidak diberi ASI dan biaya ketika anak sering sakit jika tidak diberi ASI. Sedangkan untuk produk pijat bayi bisa dibandingkan antara biaya yang dikeluarkan untuk pelayanan pijat bayi dengan biaya ketika anak sering sakit atau waktu yang terbuang ketika anak sering rewel.

3. Strategi tempat

Tempat adalah sebagian besar dimana dan kapan target sasaran akan dianjurkan untuk menjalankan perilaku yang diinginkan. Strategi tempat untuk program Kampung ASI mungkin ttidak terlalu difokuskan, namun bisa diberikan penekanan kepada masyarakat terutama jangka waktu pemberian ASI Eksklusif yaitu saat bayi umur $0 \mathrm{~s} / \mathrm{d} 6$ bulan, hanya ASI saja tanpa makanan pendamping yang lain. Sedangkan untuk pelayanan pijat bayi strategi tempat yang diberikan penekanan yaitu tentang jam buka layanan serta frekuensi yang diharapkan bayi untuk dipijat. Misalnya jam buka pelayanan pijat bayi di Puskesmas Sememi setiap hari pukul $07.30 \mathrm{~s} / \mathrm{d} 11.00 \mathrm{WIB}$, Minggu tutup. Kemudian untuk frekuensinya 2 minggu sekali bayi disarankan untuk di pijat.

4. Strategi Promosi

Informasi tentang manfaat produk dan fitur, harga yang wajar, dan aksesibilitas yang mudah membutuhkan komunikasi yang efefktif dan efisien untuk dibawa ke target sasaran dan menginspirasi tindakan. Pesan bisa disampaikan melalui berbagai saluran komunikasi (termasuk saluran media) seperti iklan, hubungan masyarakat, komunikasi, sponsor, even dan penjualan personal dan dari mulut ke mulut. Program kampung ASI dan pijat bayi mempunyai target yang sudah jelas. Program kampung ASI yang sasarannya individu dan masyarakat memerlukan saluran promosi yang lebih lengkap. Strategi promosi untuk tokoh masyarakat terutama lurah dan perangkatnya agar sepakat untuk mengeluarkan peraturan yang mewajibkan ibu bayi dan balita memberikan ASI untuk anaknya adalah dengan advokasi. Sedangkan individunya yaitu ibu bayi $n$ balita melalui edukasi serta promosi dari mulut ke mulut. Pelayanan pijat bayi bisa menggunakan berbagai media promosi, dipilih yang paling sesuai dengan target sasaran.

\section{KESIMPULAN}

1. Berdasarkan hasil survei kebutuhan dan pengetahuan tentang pelayanan kesehatan di Puskesmas Sememi, sebagian besar masyarakat di wilayah kerja sememi membutuhkan semua pelayanan kesehatan yang sudah disediakan/dijalankan oleh Puskesmas Sememi, namun masyarakat masih banyak yang belum tahu tentang keberadaan pelayanan tersebut.

2. Dari 9 (sembilan) jenis kegiatan/pelayanan kesehatan yang paling menjadi prioritas masalah adalah program kampung ASI dan pelayanan pijat bayi. Hal tersebut menjadi prioritas dikarenakan semua masyarakat menyatakan membutuhkan program/ pelayanan tersebut namun lebih dari $50 \%$ masyarakat tidak tahu sehingga tingkat partisipasi masyarakatnya menjadi kurang optimal.

\section{SARAN}

1. Untuk meningkatkan partisipasi masyarakat dalam pelayanan pijat bayi dan kampung ASI maka Puskesmas Sememi bisa menggunakan pendekatan sosial marketing.

2. Tahapan sosial marketing yang perlu dioptimalkan di Puskesmas Sememi adalah identifikasi faktor pendorong dan penghambat masyarakat dalam melakukan perubahan perilaku sesuai yang diinginkan setiap program serta penggunaan bauran pemasaran 4P (Produk, Price, Place, Promotion).

3. Untuk meningkatkan pengetahuan masyarakat terkait produk pelayanan di Puskesmas Sememi bisa dengan mengoptimalkan strategi promosi melalui berbagai media komunikasi. 


\section{DAFTAR PUSTAKA}

Profil Puskesmas Sememi Kota Surabaya Tahun 2014, Surabaya: Puskesmas Sememi

Profil Dinas Kesehatan Kota Surabaya Tahun 2014. Surabaya: Dinas Kesehatan Kota Surabaya

http://www.indonesian-publichealth.com/pelaksanaan-survei-akreditasi-puskesmas/.

Diakses tanggal 1 September 2016

Supriyanto, S., Wulandari, R.D,, 2011. Manajemen Mutu Pelayanan Kesehatan. Health Advocacy. Surabaya 